\title{
Analisis Biaya Dan Waktu Dengan Metode Earned Value Pada Proyek Jumeirah Pecatu Beach Resort
}

\author{
Made Ramda Putra ${ }^{1)}$, I Wayan Yansen ${ }^{2)}$, A.A. Diah Parami Dewi ${ }^{2)}$ \\ ${ }^{1}$ Mahasiswa Program Studi Teknik Sipil, Fakultas Teknik, Universitas Udayana, Denpasar \\ ${ }^{2}$ Dosen Program Studi Teknik Sipil, Fakultas Teknik, Universitas Udayana, Denpasar \\ email: Ramdaputra@gmail.com
}

\begin{abstract}
Abstrak
Proyek konstruksi memiliki target yang harus dipenuhi baik dari segi biaya, mutu, dan waktu. Agar dapat mencapai target, diperlukan pengendalian untuk memantau dan mengkaji hasil agar tercapai sesuai rencana, dengan pemakaian sumber daya yang efisien dan efektif. Biaya dan waktu adalah hal penting dalam proyek selain mutu. Oleh karena itu perlu dilakukan pengawasan dan pengendalian biaya dan waktu proyek. Jumeirah Pecatu Beach Resort dipilih sebagai studi karena mengalami keterlambatan yang berdampak pada biaya proyek. Tujuan penelitian ini adalah untuk mengetahui biaya total dan waktu akhir untuk menyelesaikan proyek. Metode yang digunakan dalam penelitian ini adalah metode earned value. Pada penelitian ini, data yang dikumpulkan berupa data sekunder yaitu rab, time schedule, dan laporan bulanan. Data tersebut didapat langsung dari proyek. Hasil dari penelitian didapat pada bulan ke-24 adalah ACWP $=$ Rp.182.018.842.243, BCWP $=$ Rp.176.487.889.443,2, dan $B C W S=R p .207 .826 .542 .672,3$. Pada bulan ke-24, proyek mengalami pembengkakan biaya yang dilihat dari nilai indeks kinerja biaya $(C P I)=0,96961<1$. Dari aspek jadwal, proyek mengalami keterlambatan dilihat dari nilai indeks kenerja jadwal $(S P I)=0,84921<1$. Dengan demikian diprediksikan proyek akan mengeluarkan biaya sebesar Rp.311.276.344.152,2 dimana biaya ini lebih besar dari anggaran = Rp.301.817.681.818 (kenaikan sebesar Rp.9.458.662.334). Untuk perdiksi waktu akhir proyek diperlukan 35,78 bulan untuk selesai dimana mengalami keterlambatan 1,78 bulan dari yang direncanakan.
\end{abstract}

Kata kunci ; biaya, jadwal, nilai hasil, proyek konstruksi.

\begin{abstract}
Construction project development is developing along with technology advance. Construction project has targets that must be achieve both in terms of cost, quality, and time. In order to reach the targets, controls are required to monitor and reviewing the result to be achieve as planned, with efficient and effective resources use. Cost and time are important in a construction project other than quality, so it is necessary to supervise and control the cost and time of construction project. Jumeirah Pecatu Beach Resort was chosen as a study because it experiencing delays that impact on project cost. The purpose of this research is to know final cost and end time for finish the project. The method used in this research is Earned Value Method. In this research, data were collected in the form of secondary data that is cost estimate plan, time schedule, and monthly report. The data obtained directly from the project. Result from the research were obtained at month 24th is that $A C W P=I D R$ 182.018.842.243, $B C W P=I D R$ 176.487.889.443,2, and BCWS = IDR 207.826.542.672,3. On the month 24th can be said construction project spend more that can be seen from the cost performance index $(C P I)=0,96961<1$. From aspect of schedule, construction project delays that can be seen from schedule performance index $(S P I)=$ $0,84921<1$. Therefor, predicted the project will be spend cost as much IDR 311.276.344.152,2, where the cost of construction project is more than budget $=I D R 301.817 .681 .818$ (where spend more $=I D R$ 9.458.662.334). The prediction for final time of construction project required 35,78 months to finish the construction project where project delayed by 1,78 month from the planned.
\end{abstract}

Keywords ; cost, schedule, earned value, construction project. 


\section{PENDAHULUAN}

Pembangunan proyek konstruksi telah berkembang sejalan dengan perkembangan dan kemajuan teknologi, baik dari segi fisik maupun biaya. Suatu proyek memiliki sumber daya yang terbatas, oleh karena itu proyek membutuhkan manajemen mulai dari awal hingga akhir proyek selesai. Setiap proyek konstruksi pasti memiliki target yang harus dipenuhi baik dari segi biaya, mutu, dan waktu. Oleh karena itu, diperlukan upaya untuk memenuhi target yang merupakan kegiatan manajemen konstruksi, mencakup tahap perencanaan, pelaksanaan dan pengawasan; keseluruhan tahap ini merupakan rangkaian penyelenggaraan proyek guna menghasilkan produk konstruksi yang bermutu dan handal (Willar dan Pangemanan, 2020). Pada umumnya, pada tahap pelaksanaan dan pengawasan sering terjadi penyimpangan biaya dan waktu sehingga diperlukan cara pengendalian yang tepat.

Pengendalian proyek merupakan suatu usaha sistematis untuk menentukan standar yang sesuai dengan perencanaan dengan tindakan yang diperlukan agar sumber daya dapat digunakan secara efektif dan efisien (Soeharto, 1997). Pengendalaian dilakukan untuk memantau dan mengkaji hasil kegiatan agar sesuai dengan rencana dan pemakaian sumber daya yang efisien dan efektif; sumber daya proyek termasuk biaya, material, peralatan, dan tenaga kerja. Pengendalian proyek harus dapat meminimalisasi segala penyimpangan yang dapat terjadi selama berlangsungnya kegiatan proyek (Husen, 2011).

Biaya proyek konstruksi terdiri dari dua jenis yaitu biaya langsung (direct cost) dan biaya tidak langsung (indirect cost) (Soeharto, 1997). Terdapat banyak metode yang dapat digunakan untuk mengendalikan biaya dan waktu suatu proyek, seperti metode Varians, metode nilai hasil (Earned Value), metode PERT, metode jalur kritis (CPM), dan metode Least Cost. Metode nilai hasil (Earned Value) merupakan perkembangan dari konsep analisis Varians, dimana dalam metode Earned Value dapat diketahui kinerja kegiatan yang sedang dilakukan serta dapat meningkatkan efektivitas dalam memantau kegiatan proyek dari segi biaya dan waktu.

Peneltian ini dilakukan pada proyek Jumeirah Pecatu Beach Resort, dimana pada pelaksanaannya terjadi penyimpangan pada biaya dan waktu. Pada pelaksanaan bulan ke-24 telah terjadi keterlambatan proyek sebesar $10,38 \%$. Untuk itu, studi penelitian ini bertujuan menganalisis besaran keterlambatan waktu dan pengaruhnya terhadap biaya proyek, dan pada akhirnya dapat memperkirakan besaran biaya dan waktu tambahan yang diperlukan agar proyek dapat selesai dikerjakan. Keterlambatan proyek yang dapat mempengaruhi kinerja biaya dan waktu proyek disebabkan oleh berbagai faktor, antara lain kerusakan alat, perubahan gambar oleh konsultan perencana dan perubahan desain oleh pemilik proyek (Maromi dan Indryani, 2015).

\section{DASAR TEORI}

\section{Metode}

Analisis data pada penelitian ini menggunakan metode nilai hasil (Earned Value), dimana metode ini merupakan perkembangan dari konsep Analisis Varians. Metode Earned Value mengkombinasikan biaya, jadwal dan prestasi pekerjaan. Konsep ini dapat memperkirakan kinerja proyek di waktu mendatang (Castollani dkk., 2020).

\section{A. Metode Analisis Varians}

Metode ini menghitung jumlah unit yang diselesaikan kemudian membandingkan dengan perencanaan, atau melihat catatan penggunaan sumber daya dan membandingkan lagi dengan anggaran 
proyek yang tersedia (Soeharto, 1999). Terdapat dua varians yaitu varians biaya dan varians waktu atau jadwal.

\section{B. Metode Nilai Hasil (Earned Value)}

Metode Nilai Hasil (Earned Value) adalah perkembangan dari Metode Analisis Varians, dimana metode Nilai Hasil (Earned Value) merupakan kombinasi dari biaya, jadwal, dan prestasi. Konsep metode Earned Value selain menyajikan dimensi biaya aktual dan biaya rencana, juga menyajikan dimensi besarnya pekerjaan fisik yang telah diselesaikan (Widiasanti dan Lenggogeni, 2014). Metode ini dapat menunjukkan apakah kemajuan pelaksanaan proyek senilai dengan pemakaian anggarannya. Walaupun tidak dapat diabaikan, kemajuan pelaksanaan kegiatan proyek konstruksi mengutamakan pula peran organisasi kontraktor sebagai penyelenggara proyek yang utama (Willar dan Trigunarsyah, 2021).

Beberapa hasil penelitian sebelumnya yang menggunakan metode Earned Value dalam mengendalikan biaya dan waktu proyek konstruksi, menemukan manfaat dari penerapan metode ini, antara lain, untuk menghindari kerugian proyek (Kartikasari, 2014), dapat memperkirakan biaya dan waktu penyelesaian proyek (Sediyanto dan Hidayat, 2017; Zakariyya dkk., 2020), dan dapat menginformasikan kinerja proyek saat pelaksanaan (Auzan dkk., 2017; Gardjito, 2017).

Metode Earned Value menggunakan rumus sebagai berikut (Soeharto, 1997):

Nilai Hasil $=(\%) \mathrm{x}(\mathrm{RAB})$

dimana:

$$
\begin{array}{ll}
\% & =\text { persentasi pekerjaan selesai. } \\
\text { RAB } & =\text { anggaran biaya berdasarkan nilai kontrak. }
\end{array}
$$

Dalam metode Earned Value, terdapat tiga indikator yang dapat digunakan untuk menganalisis kinerja proyek dan dapat membuat perkiraan sasaran akhir proyek terhadap waktu dan biaya. Indikator-indikator yang dimaksud adalah sebagai berikut:

\section{Actual Cost of Work Performance (ACWP)}

ACWP adalah jumlah biaya aktual yang dikeluarkan untuk pekerjaan yang telah selesai atau telah dilaksanakan. Nilai ACWP adalah biaya - biaya yang diperoleh dari data proyek menyangkut data akutansi atau laopran biaya bulanan proyek. Laporan biaya bulanan proyek terdiri dari item pekerjaan, persentase pekerjaan dan biaya untuk setiap pekerjaannya.

\section{Budgeted Cost of Work Performance (BCWP)}

BCWP adalah indikator yang menunjukan nilai hasil dari prestasi pekerjaan yang telah dilaksanakan terhadap biaya anggaran yang ada untuk pekerjaan-pekerjaan tersebut.

\section{Budgeted Cost of Work Schedule (BCWS)}

BCWS adalah indikator yang menunjukan anggaran untuk suatu item pekerjaan yang disusun atau direncanakan sesuai dengan jadwal pelaksanaan. Disini ada perpaduan antara biaya, item pekerjaan, dan jadwal. Dimana pada setiap elemen pekerjaan telah diberi alokasi biaya jadwal yang menjadi tolak ukur dalam pelaksanaan pekerjaan. (Soeharto, 2001). Dengan ketiga parameter tersebut dapat diketahui presentase rencana anggaran, presentase perkembangan proyek, serta presentase pengeluaran proyek; hasil analisis dengan ketiga parameter tersebut dapat menginformasikan terjadinya kelebihan biaya proyek dan waktu proyek, jika terjadi keterlambatan pengerjaan proyek (Prasetya, 2018).

\section{Varians Biaya dan Jadwal Terpadu}

Varians biaya (CV) dan varians waktu (SV) dapat dihitung dengan rumus sebagai berikut (Soeharto, 2001): 


$$
\begin{aligned}
& \mathrm{CV}=\mathrm{BCWP}-\mathrm{ACWP} \\
& \mathrm{SV}=\mathrm{BCWP}-\mathrm{BCWS}
\end{aligned}
$$

Kriteria untuk kedua indikator tersebut seperti pada Tabel 1 (Soeharto, 2001).

\begin{tabular}{|c|c|c|}
\hline $\begin{array}{l}\text { Varians } \\
\text { Jadwal }\end{array}$ & $\begin{array}{c}\text { Varians } \\
\text { Biaya }\end{array}$ & Keterangan \\
\hline Positif & Positif & $\begin{array}{l}\text { Pekerjaan terlaksana lebih cepat dari jadwal dengan biaya lebih kecil dari } \\
\text { anggaran. }\end{array}$ \\
\hline Nol & Positif & Pekerjaan terlaksana sesuai jadwal dengan biaya lebih rendah dari anggaran. \\
\hline Positif & Nol & Pekerjaan terlaksana sesuai anggaran dan selesai lebih cepat dari jadwal. \\
\hline Nol & Nol & Pekerjaan terlaksana sesuai jadwal dan anggaran. \\
\hline Negatif & Negatif & Pekerjaan terlambat dan biaya lebih tinggi dari anggaran. \\
\hline Nol & Negatif & Pekerjaan terlaksana sesuai jadwal dengan biaya lebih besar dari anggaran. \\
\hline Negatif & Nol & Pekerjaan terlambat dengan biaya sesuai anggaran. \\
\hline Positif & Negatif & Pekerjaan selesai lebih cepat dari jadwal dengan biaya lebih besar dari anggaran. \\
\hline
\end{tabular}

Tabel 1. Analisis Varians Terpadu

\section{Indeks Produktivitas atau Kinerja}

Indeks produktivitas atau indeks kinerja terdiri dari indeks kinerja biaya (CPI) dan indeks kinerja jadwal (SPI). Indeks kinerja biaya (CPI) merupakan faktor efisiensi dari biaya yang telah dikeluarkan dimana membandingkan nilai pekerjaan yang telah diselesaikan dengan biaya aktual yang telah dikeluarkan dalam periode yang sama dan indeks kinerja jadwal (SPI) merupakan faktor efisiensi kinerja dalam menyelesaiakn pekerjaan yang diperoleh dari perbandingan antara biaya nilai pekerjaan yang telah diselesaikan terahadap biaya yang telah direncanakan.

Rumus dalam mencari nilai CPI dan SPI adalah sebagai berikut:

$$
\mathrm{CPI}=\frac{B C W P}{A C W P} \quad \text { (4) } \quad \mathrm{SPI}=\frac{B C W P}{B C W S}
$$

Dari angka (nilai) indeks baik kinerja biaya maupun waktu, dapat dilihat bahwa:

1. Angka indeks kinerja kurang dari satu memiliki makna bahwa biaya yang dikeluarkan proyek melebihi anggaran yang direncanakan dan waktu pelaksanaan proyek lebih lama dari jadwal rencana.

2. Angka indeks kinerja lebih dari satu memiliki makna bahwa biaya yang dikeluarkan oleh proyek lebih kecil dari rencana dan waktu pelaksanaan proyek lebih cepat dari yang direncanakan.

3. Besarnya perbedaan nilai indeks dari angka satu menunjukan semakin besarnya masalah atau penyimpangan dari rencana proyek. Bila angka indeks terlalu tinggi dari satu perlu diadakan penelitian atau pengkajian kembali.

\section{E. Proyeksi Biaya dan Waktu Akhir Proyek}

Persamaan yang digunakan dalam membuat proyeksi biaya (EAC) dan jadwal akhir proyek menurut Imam Soeharto dapat dihitung berdasarkan beberapa asumsi pada Tabel 2 (Soeharto, 2001).

Tabel 2. Perhitungan EAC

\begin{tabular}{lc}
\hline \multicolumn{1}{c}{ Asumsi } & Rumus \\
\hline $\begin{array}{l}\text { Biaya kedepannya akan sama dengan biaya untuk } \\
\text { sisa pekerjaan }\end{array}$ & $E A C=A C W P+\left(\frac{B A C-B C W P}{C P I}\right)$ \\
$\begin{array}{l}\text { Biaya kedepannya dipengaruhi oleh penambahan } \\
\text { pekerjaan pada jadwal masa lalu }\end{array}$ & $E A C=A C W P+\left(\frac{B A C-B C W P}{C P I \times S P I}\right)$ \\
$\begin{array}{l}\text { Biaya kedepannya dipengaruhi dan digabungkan } \\
\text { pada beberapa proporsi indeksnya }\end{array}$ & $E A=A C W P+\left(\frac{B A C-B C W P}{0.8 C P I \times 0.2 S P I}\right)$ \\
\hline
\end{tabular}


Pada aspek waktu dimana ETS adalah perkiraan waktu penyelesaian proyek dan EAS adalah total akhir waktu pelaksanaan proyek

$$
\begin{aligned}
& \text { ETS }=\frac{\text { wakturencana-waktupelaporan }}{S P I} \\
& \text { EAS = waktu pelaporan + ETS }
\end{aligned}
$$

\section{METODE PENELITIAN}

Pada penelitian ini, terdapat langkah-langkah dalam melaksanakan penelitian yang berdasarkan pada tujuan penelitian sehingga diperoleh kesimpulan dan hasil penelitian sesuai yang diharapkan. Langkah-langkah dalam penelitian meliputi:

1. Melakukan studi pustaka tentang biaya dan waktu serta metode earned value.

2. Mengumpulkan data berupa rencana anggaran biaya, time schedule, dan laporan biaya bulanan.

3. Mengolah data untuk mendapatkan indikator-indikator berupa acwp, bcwp, dan bcws.

4. Menghitung varians biaya (CV) dan varians waktu (SV), serta indeks kinerja biaya (CPI) dan indeks kinerja waktu (SPI).

5. Menghitung asumsi biaya (ETC) dan waktu (ETS) yang akan diperlukan untuk pekerjaan yang tersisa.

6. Menghitung asumsi biaya total (EAC) dan waktu (EAS) akhir untuk menyelesaikan proyek.

\section{HASIL DAN PEMBAHASAN}

\section{Objek Penelitian}

Proyek Jumeirah Pecatu Beach Resort merupakan proyek konstruksi bangunan gedung. Proyek ini berlokasi di Pecatu, Badung, Bali. Pada Proyek Jumeirah Pecatu Beach Resort, proyek ditinjau dari bulan pertama yaitu bulan Agustus 2015 sampai dengan bulan ke-24 yaitu bulan Juli 2017, dimana proyek masih berjalan dan kondisi proyek telah menyelesaikan pekerjaan sebesar 58,475\%. Pencapaian ini tidak sesuai dengan jadwal rencana dimana proyek seharusnya telah menyelesaikan pekerjaan $68,85 \%$. Jadi proyek mengalami keterlambatan sebesar 10,38\%. Pada bulan ke-24, Juli 2017 proyek telah mengeluarkan biaya sebesar Rp.182.018.842.243,00. Analisis data dalam penelitian ini adalah sebagai berikut:

\section{A. Actual Cost of Work Performance (ACWP)}

Pada proyek Jumeriah Pecatu Beach Resort, ACWP atau biaya aktual dapat diperoleh atau dilihat pada laporan biaya bulan proyek. Untuk biaya aktual, pada proyek Jumeirah dilakukan pelaporan setiap bulan. Untuk ACWP setiap bulan ditabelkan pada Tabel 3.

\begin{tabular}{|c|c|c|c|c|c|}
\hline \multirow{2}{*}{$\begin{array}{c}\text { Bulan } \\
(\mathrm{Ke})\end{array}$} & \multicolumn{2}{|c|}{ ACWP } & \multirow{2}{*}{$\begin{array}{c}\text { Bulan } \\
(\mathrm{Ke})\end{array}$} & \multicolumn{2}{|c|}{ ACWP } \\
\hline & Perbulan & Komulatif & & Perbulan & Komulatif \\
\hline 1 & $2,370,429,427$ & $2,370,429,427$ & 8 & $13,847,639,424$ & $\begin{array}{l}51,485,700,919 \\
\end{array}$ \\
\hline 2 & $1,296,813,083$ & $3,667,242,510$ & 9 & $17,703,953,967$ & $69,189,654,886$ \\
\hline 3 & $8,631,546,074$ & $12,298,788,585$ & 10 & $9,183,731,397$ & $78,373,386,283$ \\
\hline 4 & $10,230,873,469$ & $22,529,662,054$ & 11 & 000 & $78,373,386,283$ \\
\hline 5 & 0.00 & $22,529,662,054$ & 12 & $10,349,038,108$ & $88,722,424,391$ \\
\hline 6 & $15,108,399,441$ & $37,638,061,495$ & 13 & 0.00 & $88,722,424,391$ \\
\hline 7 & 0.00 & $37,638,061,495$ & 14 & $6,875,254,174$ & $95,597,678,565$ \\
\hline
\end{tabular}

Tabel 3. Perhitungan ACWP 
Tabel 3. Perhitungan ACWP (lanjutan)

\begin{tabular}{|c|c|c|c|c|c|}
\hline \multirow{2}{*}{$\begin{array}{c}\text { Bulan } \\
(\mathrm{Ke})\end{array}$} & \multicolumn{2}{|c|}{ ACWP } & \multirow{2}{*}{$\begin{array}{c}\text { Bulan } \\
(\mathrm{Ke})\end{array}$} & \multicolumn{2}{|c|}{ ACWP } \\
\hline & Perbulan & Komulatif & & Perbulan & Komulatif \\
\hline 15 & $7,206,586,601$ & $102,804,265,166$ & 20 & 0.00 & $130,203,867,537$ \\
\hline 16 & $12,036,430,412$ & $114,840,695,578$ & 21 & $11,317,861,448$ & $141,521,728,985$ \\
\hline 17 & 0.00 & $114,840,695,578$ & 22 & $10,839,215,671$ & $152,360,944,656$ \\
\hline 18 & $8,779,307,803$ & $123,620,003,381$ & 23 & $18,601,111,735$ & $170,962,056,391$ \\
\hline 19 & $6,583,864,156$ & $130,203,867,537$ & 24 & $11,056,785,852$ & $182,018,842,243$ \\
\hline
\end{tabular}

\section{B. Budgeted Cost of Work Schedule (BCWS)}

Perhitungan biaya berdasarkan rencana (BCWS) dapat diperoleh dari time schedule dimana pada time schedule terdapat bobot pekerjaan rencana yang akan dikalikan dengan rencana anggaran biaya (rab). Hasil Perhitungan biaya berdasarkan rencana (BCWS) selama penelitian akan ditabelkan pada Tabel 4. Nilai kontak sejumlah Rp. 301,817,681,818,-

Tabel 4. Perhitungan BCWS

\begin{tabular}{cccccccc}
\hline $\begin{array}{c}\text { Bulan } \\
\text { Ke }\end{array}$ & $\begin{array}{c}\text { Bobot } \\
\text { Rencana } \\
(\mathrm{Rp})\end{array}$ & $\begin{array}{c}\text { BCWS } \\
(\mathrm{Rp})\end{array}$ & $\begin{array}{c}\text { BCWS } \\
\text { Komulatif } \\
(\mathrm{Rp})\end{array}$ & $\begin{array}{c}\text { Bulan } \\
\text { Ke }\end{array}$ & $\begin{array}{c}\text { Bobot } \\
\text { Rencana } \\
(\mathrm{Rp})\end{array}$ & $\begin{array}{c}\text { BCWS } \\
(\mathrm{Rp})\end{array}$ & $\begin{array}{c}\text { BCWS } \\
\text { Komulatif } \\
(\mathrm{Rp})\end{array}$ \\
\hline 1 & 1.26 & $3,789,373,964$ & $3,789,373,964$ & 13 & 1.13 & $3,403,275,942$ & $92,255,000,761$ \\
2 & 0.69 & $2,077,772,435$ & $5,867,146,399$ & 14 & 1.14 & $3,436,766,169$ & $95,691,766,929$ \\
3 & 2.13 & $6,431,314,766$ & $12,298,461,165$ & 15 & 2.35 & $7,105,015,167$ & $102,796,782,097$ \\
4 & 3.39 & $10,230,281,156$ & $22,528,742,321$ & 16 & 3.49 & $10,534,503,051$ & $113,331,285,148$ \\
5 & 2.50 & $7,554,469,720$ & $30,083,212,042$ & 17 & 2.54 & $7,671,020,238$ & $121,002,305,386$ \\
6 & 2.50 & $7,554,469,720$ & $37,637,681,762$ & 18 & 3.21 & $9,701,251,690$ & $130,703,557,075$ \\
7 & 2.30 & $6,930,188,616$ & $44,567,870,378$ & 19 & 4.51 & $13,600,749,235$ & $144,304,306,310$ \\
8 & 2.30 & $6,930,188,616$ & $51,498,058,994$ & 20 & 4.36 & $13,166,035,639$ & $157,470,341,949$ \\
9 & 5.86 & $17,679,989,648$ & $69,178,048,642$ & 21 & 4.36 & $13,166,035,639$ & $170,636,377,588$ \\
10 & 3,07 & 9.254 .213 .942 & 78.432 .262 .584 & 22 & 4.36 & $13,166,035,639$ & $183,802,413,228$ \\
11 & 1.73 & $5,209,731,117$ & $83,641,993,702$ & 23 & 6.54 & $19,747,469,453$ & $203,549,882,680$ \\
12 & 1.73 & $5,209,731,117$ & $88,851,724,818$ & 24 & 1.42 & $4,276,659,992$ & $207,826,542,672$ \\
\hline
\end{tabular}

\section{Budgeted Cost of Work Performance (BCWP)}

Perhitungan biaya berdasarkan prestasi pekerjaan setiap bulannya (BCWP) dapat diperoleh dari laporan bulanan proyek atau dapat juga dilihat prestasi proyek pada time schedule yang kemudian dikalikan dengan anggaran biaya (rab). Biaya berdasarkan prestasi pekerjaan (BCWP) selama penelitian akan ditabelkan pada Tabel 5. Nilai kontrak berjumlah Rp. $301,817,681,818$,-

Tabel 5. Perhitungan BCWP

\begin{tabular}{cccccccc}
\hline $\begin{array}{c}\text { Bulan } \\
\text { Ke }\end{array}$ & Bobot & $\begin{array}{c}\text { BCWP } \\
(\mathrm{Rp})\end{array}$ & $\begin{array}{c}\text { BCWP } \\
\text { Komulatif } \\
(\mathrm{Rp})\end{array}$ & $\begin{array}{c}\text { Bulan } \\
\text { Ke }\end{array}$ & $\begin{array}{c}\text { Bobot } \\
(\mathrm{Rp})\end{array}$ & $\begin{array}{c}\text { BCWP } \\
\text { Komulatif } \\
(\mathrm{Rp})\end{array}$ \\
\hline 1 & 1.26 & $3,789,373,964$ & $3,789,373,964$ & 4 & 3.39 & $10,230,281,156$ & $22,528,742,321$ \\
2 & 0.69 & $2,077,772,434$ & $5,867,146,399$ & 5 & 2.50 & $7,554,469,720$ & $30,083,212,041$ \\
3 & 2.13 & $6,431,314,765$ & $12,298,461,165$ & 6 & 2.50 & $7,554,469,720$ & $37,637,681,762$ \\
\hline
\end{tabular}


Tabel 5. Perhitungan BCWP (lanjutan)

\begin{tabular}{cccccccc}
\hline $\begin{array}{c}\text { Bulan } \\
\text { Ke }\end{array}$ & Bobot & $\begin{array}{c}\text { BCWP } \\
(\mathrm{Rp})\end{array}$ & $\begin{array}{c}\text { KCWP } \\
\text { Komulatif } \\
(\mathrm{Rp})\end{array}$ & $\begin{array}{c}\text { Bulan } \\
\text { Ke }\end{array}$ & Bobot & $\begin{array}{c}\text { BCWP } \\
(\mathrm{Rp})\end{array}$ & $\begin{array}{c}\text { BCWP } \\
\text { Komulatif } \\
(\mathrm{Rp})\end{array}$ \\
\hline 7 & 2.30 & $6,930,188,615$ & $44,567,870,378$ & 16 & 3.99 & $12,044,845,834$ & $114,841,627,931$ \\
8 & 2.30 & $6,930,188,615$ & $51,498,058,993$ & 17 & 2.45 & $7,394,533,204$ & $122,236,161,136$ \\
9 & 5.86 & $17,679,989,647$ & $69,178,048,641$ & 18 & 0.46 & $1,388,361,336$ & $123,624,522,472$ \\
10 & 3.07 & $9,254,213,942$ & $78,432,262,584$ & 19 & 2.18 & $6,579,625,463$ & $130,204,147,936$ \\
11 & 1.73 & $5,209,731,116$ & $83,641,993,701$ & 20 & 4.61 & $13,913,795,131$ & $144,117,943,068$ \\
12 & 1.73 & $5,209,731,116$ & $88,851,724,818$ & 21 & 1.59 & $4,783,810,256$ & $148,901,753,325$ \\
13 & 1.13 & $3,403,275,942$ & $92,255,000,760$ & 22 & 1.59 & $4,783,810,256$ & $153,685,563,581$ \\
14 & 1.14 & $3,436,766,168$ & $95,691,766,929$ & 23 & 6.24 & $18,833,423,345$ & $172,518,986,927$ \\
15 & 2.35 & $7,105,015,167$ & $102,796,782,096$ & 24 & 1.32 & $3,968,902,515$ & $176,487,889,443$ \\
\hline
\end{tabular}

\section{Hubungan ACWP, BCWS, dan BCWP}

Hubungan antara acwp, bcws, dan bcwp dilihat dari Gambar 2. Menunjukan bahwa saat bulan ke-24, pada perbandingan ACWP dan BCWP menunjukan bahwa biaya yang dikeluarkan proyek lebih besar dari biaya yang seharusnya dikeluarkan. Untuk perbandingan ACWP dan BCWS menunjukan bahwa nilai ACWP komulatif lebih besar dari nilai BCWS komulatif terjadi pada bulan ke 3, 4, 6, 9, dan 15. Serta pada perbandingan BCWP dan BCWS menunjukan bahwa pada bulan ke-1 sampai bulan ke-15 nilainya sama, pada bulan ke-16 dan bulan ke-17 nilai BCWP komulatif lebih besar dari nilai BCWS komulatif, lalu nilai BCWP komulatif lebih kecil dari nilai BCWS komulatif terjadi pada bulan ke-18 sampai bulan ke-24.

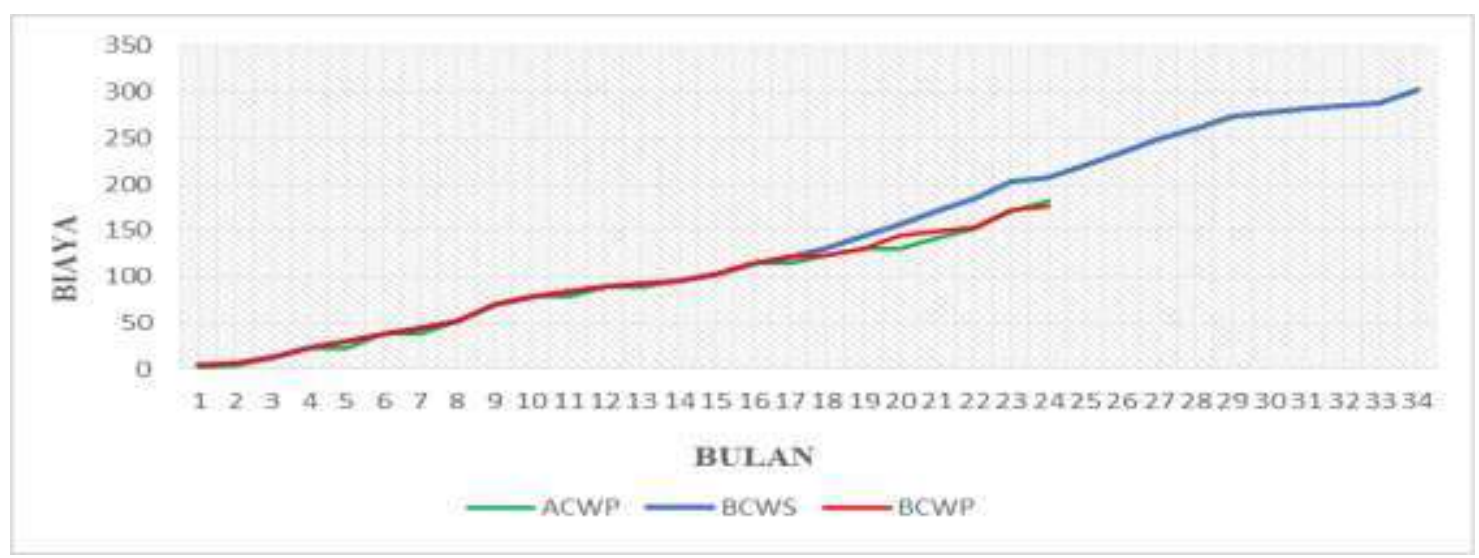

Gambar 2. Grafik ACWP, BCWS, dan BCWP

\section{E. Varians dan Indeks Kinerja}

Analisis varians dilakukan untuk memperlihatkan perbedaan antara biaya dan waktu terhadap anggaran maupun jadwal dan indeks kinerja untuk mengetahui efisiensi kinerja proyek dalam segi waktu dan biaya. Rincian varians dan indeks kinerja setiap bulan ditabelkan sebagai berikut:

Tabel 6. Varians Biaya

\begin{tabular}{cccc}
\hline $\begin{array}{c}\text { Bulan } \\
\text { Ke }\end{array}$ & $\begin{array}{c}\text { BCWP } \\
\text { (Rp) }\end{array}$ & $\begin{array}{c}\text { ACWP } \\
\text { (Rp) }\end{array}$ & \multicolumn{1}{c}{$\begin{array}{c}\text { CV } \\
\text { (Rp) }\end{array}$} \\
\hline 1 & $3,789,373,964$ & $2,370,429,427$ & $1,418,944,537$ \\
2 & $5,867,146,399$ & $3,667,242,510$ & $2,199,903,889$ \\
3 & $12,298,461,165$ & $12,298,788,585$ & $-327,420$ \\
\hline
\end{tabular}




\begin{tabular}{cccl}
\hline $\begin{array}{c}\text { Bulan } \\
\text { Ke }\end{array}$ & $\begin{array}{c}\text { BCWP } \\
(\mathrm{Rp})\end{array}$ & $\begin{array}{c}\text { ACWP } \\
(\mathrm{Rp})\end{array}$ & \multicolumn{1}{c}{$\begin{array}{c}\text { CV } \\
(\mathrm{Rp})\end{array}$} \\
\hline 4 & $22,528,742,321$ & $22,529,662,054$ & $-919,733$ \\
5 & $30,083,212,042$ & $22,529,662,054$ & $7,553,549,988$ \\
6 & $37,637,681,762$ & $37,638,061,495$ & $-379,733$ \\
7 & $44,567,870,378$ & $37,638,061,495$ & $6,929,808,883$ \\
8 & $51,498,058,994$ & $51,485,700,919$ & $12,358,075$ \\
9 & $69,178,048,642$ & $69,189,654,886$ & $-11,606,244$ \\
10 & $78,432,262,585$ & $78,373,386,283$ & $58,876,302$ \\
11 & $83,641,993,702$ & $78,373,386,283$ & $5,268,607,419$ \\
12 & $88,851,724,818$ & $88,722,424,391$ & $129,300,427$ \\
13 & $92,255,000,761$ & $88,722,424,391$ & $3,532,576,370$ \\
14 & $95,691,766,929$ & $95,597,678,565$ & $94,088,364$ \\
15 & $102,796,782,097$ & $102,804,265,166$ & $-7,483,069$ \\
16 & $114,841,627,932$ & $114,840,695,578$ & 932,354 \\
17 & $122,236,161,136$ & $114,840,695,578$ & $7,395,465,558$ \\
18 & $123,624,522,473$ & $123,620,003,381$ & $4,519,092$ \\
19 & $130,204,147,936$ & $130,203,867,537$ & 280,399 \\
20 & $144,117,943,068$ & $130,203,867,537$ & $13,914,075,531$ \\
21 & $148,901,753,325$ & $141,521,728,985$ & $7,380,024,340$ \\
22 & $153,685,563,582$ & $152,360,944,656$ & $1,324,618,926$ \\
23 & $172,518,986,927$ & $170,962,056,391$ & $1,556,930,536$ \\
24 & $176,487,889,443$ & $182,018,842,243$ & $-5,530,952,800$ \\
\hline
\end{tabular}

Dapat dilihat pada Tabel 6, nilai varians biaya pada bulan ke-24, Juli 2017 Rp.5.530.952.800. Hal ini menunjukan bahwa pada bulan ke-24 biaya yang dikeluarkan proyek melebihi anggaran yang telah direncanakan.

Tabel 7. Indeks Kinerja Biaya

\begin{tabular}{cccccccc}
\hline $\begin{array}{c}\text { Bulan } \\
\text { Ke }\end{array}$ & $\begin{array}{c}\text { BCWP } \\
(\text { Rp })\end{array}$ & $\begin{array}{c}\text { ACWP } \\
(\text { Rp })\end{array}$ & $\begin{array}{c}\text { CPI } \\
(\text { Rp })\end{array}$ & $\begin{array}{c}\text { Bulan } \\
\text { Ke }\end{array}$ & $\begin{array}{c}\text { BCWP } \\
(\text { Rp })\end{array}$ & $\begin{array}{c}\text { ACWP } \\
(\text { Rp })\end{array}$ & $\begin{array}{c}\text { CPI } \\
(\text { Rp })\end{array}$ \\
\hline 1 & $3,789,373,964$ & $2,370,429,427$ & 1.59860 & 13 & $92,255,000,761$ & $88,722,424,391$ & 1.03982 \\
2 & $5,867,146,399$ & $3,667,242,510$ & 1.59988 & 14 & $95,691,766,929$ & $95,597,678,565$ & 1.00098 \\
3 & $12,298,461,165$ & $12,298,788,585$ & 0.99997 & 15 & $102,796,782,097$ & $102,804,265,166$ & 0.99993 \\
4 & $22,528,742,321$ & $22,529,662,054$ & 0.99996 & 16 & $114,841,627,932$ & $114,840,695,578$ & 1.00001 \\
5 & $30,083,212,042$ & $22,529,662,054$ & 1.33527 & 17 & $122,236,161,136$ & $114,840,695,578$ & 1.06440 \\
6 & $37,637,681,762$ & $37,638,061,495$ & 0.99999 & 18 & $123,624,522,473$ & $123,620,003,381$ & 1.00004 \\
7 & $44,567,870,378$ & $37,638,061,495$ & 1.18412 & 19 & $130,204,147,936$ & $130,203,867,537$ & 1.00000 \\
8 & $51,498,058,994$ & $51,485,700,919$ & 1.00024 & 20 & $144,117,943,068$ & $130,203,867,537$ & 1.10686 \\
9 & $69,178,048,642$ & $69,189,654,886$ & 0.99983 & 21 & $148,901,753,325$ & $141,521,728,985$ & 1.05215 \\
10 & $78,432,262,585$ & $78,373,386,283$ & 1.00075 & 22 & $153,685,563,582$ & $152,360,944,656$ & 1.00869 \\
11 & $83,641,993,702$ & $78,373,386,283$ & 1.06722 & 23 & $172,518,986,927$ & $170,962,056,391$ & 1.00911 \\
12 & $88,851,724,818$ & $88,722,424,391$ & 1.00146 & 24 & $176,985,888,618$ & $182,018,842,243$ & 0.96961 \\
\hline
\end{tabular}

Seperti pada Tabel 7, pada bulan ke-24, Juli 2017. Nilai indeks kinerja (CPI) yaitu 0,96961. Karena nilai CPI kurang dari satu, proyek dapat dikatakan mengeluarkan biaya lebih dari anggaran yang direncanalan. Nilai varians jadwal (SV) pada bulan ke-24, Juli 2017 sebesar -Rp.31.338.653.229. Ini menunjukan bahwa pada bulan ke-24 waktu pelaksanaan proyek mengalami keterlambatan dari yang direncanakan. 
Tabel 8. Varians Jadwal

\begin{tabular}{cccccccc}
\hline $\begin{array}{c}\text { Bulan } \\
\text { Ke }\end{array}$ & $\begin{array}{c}\text { BCWP } \\
(\mathrm{Rp})\end{array}$ & $\begin{array}{c}\text { BCWS } \\
(\mathrm{Rp})\end{array}$ & $\begin{array}{c}\text { SV } \\
(\mathrm{Rp})\end{array}$ & $\begin{array}{c}\text { Bulan } \\
\text { Ke }\end{array}$ & $\begin{array}{c}\text { BCWP } \\
(\mathrm{Rp})\end{array}$ & $\begin{array}{c}\text { BCWS } \\
(\mathrm{Rp})\end{array}$ & $\begin{array}{c}\text { SV } \\
(\mathrm{Rp})\end{array}$ \\
\hline 1 & $3,789,373,964$ & $3,789,373,964$ & 0 & 13 & $92,255,000,761$ & $92,255,000,761$ & 0 \\
2 & $5,867,146,399$ & $5,867,146,399$ & 0 & 14 & $95,691,766,929$ & $95,691,766,929$ & 0 \\
3 & $12,298,461,165$ & $12,298,461,165$ & 0 & 15 & $102,796,782,097$ & $102,796,782,097$ & 0 \\
4 & $22,528,742,321$ & $22,528,742,321$ & 0 & 16 & $114,841,627,932$ & $113,331,285,148$ & $1,510,342,784$ \\
5 & $30,083,212,042$ & $30,083,212,042$ & 0 & 17 & $122,236,161,136$ & $121,002,305,386$ & $1,233,855,751$ \\
6 & $37,637,681,762$ & $37,637,681,762$ & 0 & 18 & $123,624,522,473$ & $130,703,557,075$ & $-7,079,034,603$ \\
7 & $44,567,870,378$ & $44,567,870,378$ & 0 & 19 & $130,204,147,936$ & $144,304,306,310$ & $-14,100,158,374$ \\
8 & $51,498,058,994$ & $51,498,058,994$ & 0 & 20 & $144,117,943,068$ & $157,470,341,949$ & $-13,352,398,881$ \\
9 & $69,178,048,642$ & $69,178,048,642$ & 0 & 21 & $148,901,753,325$ & $170,636,377,588$ & $-21,734,624,263$ \\
10 & $78,432,262,585$ & $78,432,262,585$ & 0 & 22 & $153,685,563,582$ & $183,802,413,228$ & $-30,116,849,646$ \\
11 & $83,641,993,702$ & $83,641,993,702$ & 0 & 23 & $172,518,986,927$ & $203,549,882,680$ & $-31,030,895,753$ \\
12 & $88,851,724,818$ & $88,851,724,818$ & 0 & 24 & $176,487,889,443$ & $207,826,542,672$ & $-31,338,653,229$ \\
\hline
\end{tabular}

Seperti pada Tabel 9, nilai indeks kinerja jadwal pada bulan ke-24, Juli 2017 bernilai kurang dari satu yaitu 0,84921 , maka dapat dikatakan proyek mengalami keterlambatan dari waktu yang direncanakan.

Tabel 9. Indeks Kinerja Jadwal

\begin{tabular}{cccccccc}
\hline $\begin{array}{c}\text { Bulan } \\
\text { Ke }\end{array}$ & $\begin{array}{c}\text { BCWP } \\
(\mathrm{Rp})\end{array}$ & $\begin{array}{c}\text { BCWS } \\
(\mathrm{Rp})\end{array}$ & $\begin{array}{c}\text { SPI } \\
(\mathrm{Rp})\end{array}$ & $\begin{array}{c}\text { Bulan } \\
\text { Ke }\end{array}$ & $\begin{array}{c}\text { BCWP } \\
(\mathrm{Rp})\end{array}$ & $\begin{array}{c}\text { BCWS } \\
(\mathrm{Rp})\end{array}$ & $\begin{array}{c}\text { SPI } \\
(\mathrm{Rp})\end{array}$ \\
\hline 1 & $3,789,373,964$ & $3,789,373,964$ & 1.00000 & 13 & $92,255,000,761$ & $92,255,000,761$ & 1.00000 \\
2 & $5,867,146,399$ & $5,867,146,399$ & 1.00000 & 14 & $95,691,766,929$ & $95,691,766,929$ & 1.00000 \\
3 & $12,298,461,165$ & $12,298,461,165$ & 1.00000 & 15 & $102,796,782,097$ & $102,796,782,097$ & 1.00000 \\
4 & $22,528,742,321$ & $22,528,742,321$ & 1.00000 & 16 & $114,841,627,932$ & $113,331,285,148$ & 1.01333 \\
5 & $30,083,212,042$ & $30,083,212,042$ & 1.00000 & 17 & $122,236,161,136$ & $121,002,305,386$ & 1.01020 \\
6 & $37,637,681,762$ & $37,637,681,762$ & 1.00000 & 18 & $123,624,522,473$ & $130,703,557,075$ & 0.94584 \\
7 & $44,567,870,378$ & $44,567,870,378$ & 1.00000 & 19 & $130,204,147,936$ & $144,304,306,310$ & 0.90229 \\
8 & $51,498,058,994$ & $51,498,058,994$ & 1.00000 & 20 & $144,117,943,068$ & $157,470,341,949$ & 0.91521 \\
9 & $69,178,048,642$ & $69,178,048,642$ & 1.00000 & 21 & $148,901,753,325$ & $170,636,377,588$ & 0.87263 \\
10 & $78,432,262,585$ & $78,432,262,585$ & 1.00000 & 22 & $153,685,563,582$ & $183,802,413,228$ & 0.83615 \\
11 & $83,641,993,702$ & $83,641,993,702$ & 1.00000 & 23 & $172,518,986,927$ & $203,549,882,680$ & 0.84755 \\
12 & $88,851,724,818$ & $88,851,724,818$ & 1.00000 & 24 & $176,487,889,443$ & $207,826,542,672$ & 0.84921 \\
\hline
\end{tabular}

\section{F. Perkiraan Biaya dan Waktu Akhir Proyek}

Dengan data-data diatas maka dilanjutkan dengan memperkirakan kondisi akhir proyek, dengan asumsi bahwa keadaan yang akan dating akan sama dengan kondisi saat waktu pelaporan.

Untuk mengetahui biaya dan waktu akhir, terlebih dahulu mencari biaya dan waktu untuk pekerjaan tersisa. Untuk biaya pekerjaan tersisa didapat dinilai sebesar Rp.129.257.501.909 dan waktu pekerjaan tersisa 11,78 bulan. Rincian biaya dan waktu untuk pekerjaan tersisa setiap bulan disajikan pada Tabel 10. 
Tabel 10. Biaya dan Waktu Pekerjaan Tersisa

\begin{tabular}{cccccc}
\hline $\begin{array}{c}\text { Bulan } \\
\text { Ke }\end{array}$ & ETC & ETS & $\begin{array}{c}\text { Bulan } \\
\text { Ke }\end{array}$ & ETC & ETS \\
\hline 1 & $186.430 .549 .667,83$ & 33,00 & 13 & $201.538 .225 .266,86$ & 21,00 \\
2 & $184.983 .007 .162,55$ & 32,00 & 14 & $205.923 .242 .800,74$ & 20,00 \\
3 & $289.526 .928 .475,78$ & 31,00 & 15 & $199.035 .387 .403,84$ & 19,00 \\
4 & $279.300 .341 .428,33$ & 30,00 & 16 & $186.974 .535 .901,63$ & 17,76 \\
5 & $203.505 .056 .707,41$ & 29,00 & 17 & $168.716 .577 .454,10$ & 16,83 \\
6 & $264.182 .665 .412,40$ & 28,00 & 18 & $178.186 .645 .498,40$ & 16,92 \\
7 & $217.250 .322 .719,72$ & 27,00 & 19 & $171.613 .164 .305,84$ & 16,62 \\
8 & $250.259 .553 .207,46$ & 26,00 & 20 & $142.474 .389 .084,99$ & 15,30 \\
9 & $232.678 .663 .944,75$ & 25,00 & 21 & $145.336 .949 .407,62$ & 14,90 \\
10 & $223.217 .731 .767,72$ & 24,00 & 22 & $146.855 .364 .566,31$ & 14,35 \\
11 & $204.432 .806 .125,46$ & 23,00 & 23 & $128.131 .814 .132,09$ & 12,98 \\
12 & $212.656 .040 .796,31$ & 22,00 & 24 & $129.257 .501 .909,20$ & 11,78 \\
\hline
\end{tabular}

Maka untuk biaya total proyek dan waktu akhir pelaksanan proyek akan didapat, dengan asumsi bahwa pada keadaan yang akan datang akan sama dengan kondisi saat waktu pelaporan. Untuk total biaya akhir proyek didapat nilai sebesar Rp.311.276.344.152 dan waktu akhir pelaksanaan proyek yaitu 35,78 bulan. Rekapitulasi hasil analisa setiap bulannya ditabelkan pada Tabel 11 dan grafik persentase ACWP, BCWS, dan BCWP akan disajikan pada Gambar 3.

Dengan ketiga parameter tersebut dapat diketahui presentase rencana anggaran, presentase perkembangan proyek, serta presentase pengeluaran proyek; hasil analisis dengan ketiga parameter tersebut dapat menginformasikan terjadinya kelebihan biaya proyek dan waktu proyek, jika terjadi keterlambatan pengerjaan proyek (Prasetya, 2018).

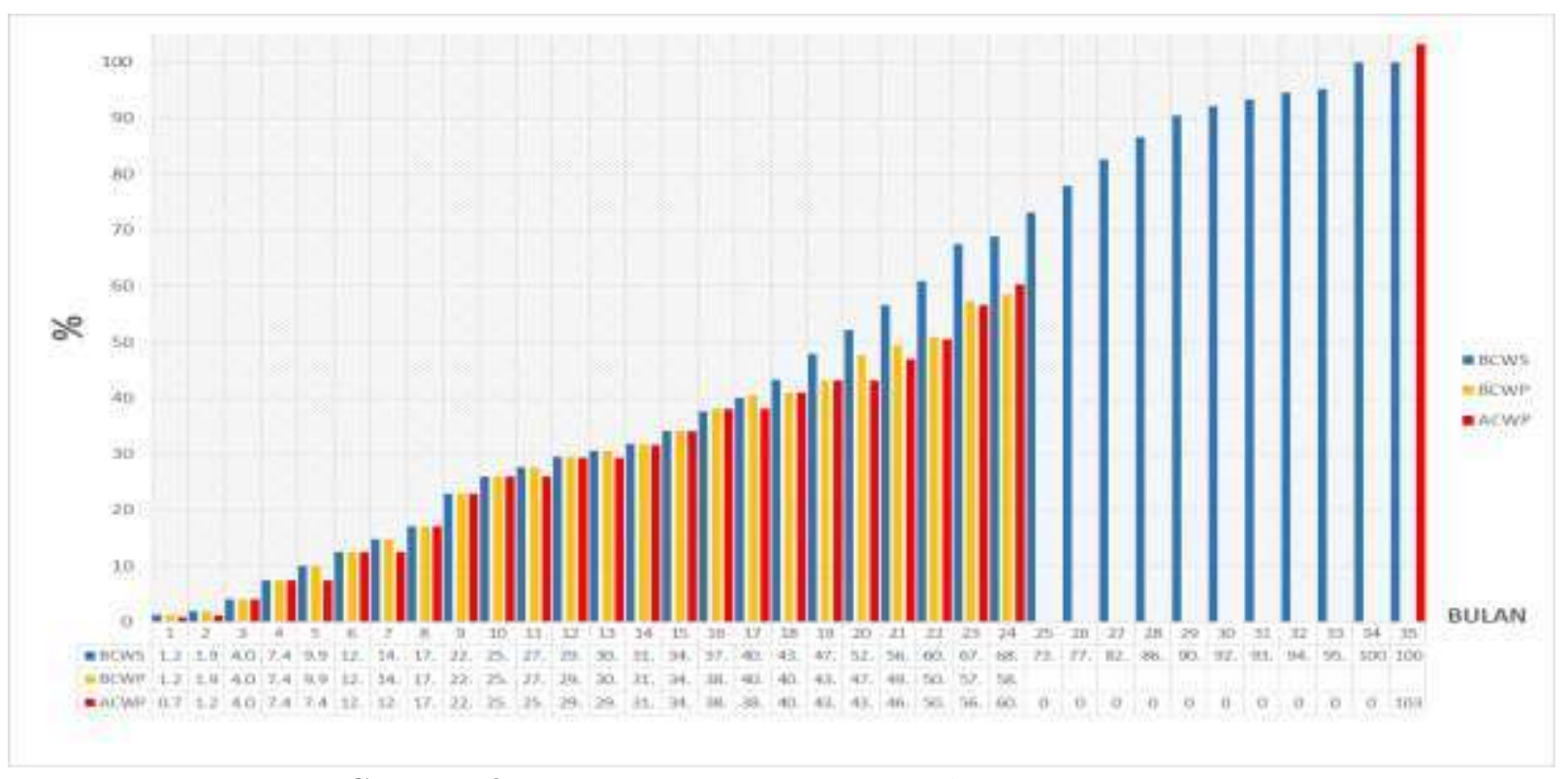

Gambar 3. Persentase ACWP, BCWS, dan BCWP 
Tabel 11. Rekapitulasi Hasil Setiap Bulan

\begin{tabular}{|c|c|c|c|c|c|c|c|c|c|c|c|}
\hline $\begin{array}{l}\text { Bulan } \\
\text { ke }\end{array}$ & ACWP & BCWP & BCWS & $\mathrm{CV}$ & SV & CPI & SPI & ETC & ETS & EAC & EAS \\
\hline 1 & $2,370,429,427.16$ & $3,789,373,964.31$ & $3,789,373,964.31$ & $1,418,944,537$ & 0 & 1.59860 & 1.00000 & $186,430,549,667.83$ & 33.00 & $188,800,979,094.99$ & 34.00 \\
\hline 2 & $3,667,242,510.16$ & $5,867,146,399.23$ & $5,867,146,399.23$ & $2,199,903,889$ & 0 & 1.59988 & 1.00000 & $184,983,007,162.55$ & 32.00 & $188,650,249,672.71$ & 34.00 \\
\hline 3 & $12,298,788,585.00$ & $12,298,461,165.09$ & $12,298,461,165.09$ & $-327,420$ & 0 & 0.99997 & 1.00000 & $289,526,928,475.78$ & 31.00 & $301,825,717,060.78$ & 34.00 \\
\hline 4 & $22,529,662,054.00$ & $22,528,742,321.28$ & $22,528,742,321.28$ & $-919,733$ & 0 & 0.99996 & 1.00000 & $279,300,341,428.33$ & 30.00 & $301,830,003,482.33$ & 34.00 \\
\hline 5 & $22,529,662,054.00$ & $30,083,212,041.70$ & $30,083,212,041.70$ & $7,553,549,988$ & 0 & 1.33527 & 1.00000 & $203,505,056,707.41$ & 29.00 & $226,034,718,761.41$ & 34.00 \\
\hline 6 & $37,638,061,495.00$ & $37,637,681,762.12$ & $37,637,681,762.12$ & $-379,733$ & 0 & 0.99999 & 1.00000 & $264,182,665,412.40$ & 28.00 & $301,820,726,907.40$ & 34.00 \\
\hline 7 & $37,638,061,495.00$ & $44,567,870,378.05$ & $44,567,870,378.05$ & $6,929,808,883$ & 0 & 1.18412 & 1.00000 & $217,250,322,719.72$ & 27.00 & $254,888,384,214.72$ & 34.00 \\
\hline 8 & $51,485,700,919.00$ & $51,498,058,993.98$ & $51,498,058,993.98$ & $12,358,075$ & 0 & 1.00024 & 1.00000 & $250,259,553,207.46$ & 26.00 & $301,745,254,126.46$ & 34.00 \\
\hline 9 & $69,189,654,886.00$ & $69,178,048,641.80$ & $69,178,048,641.80$ & $-11,606,244$ & 0 & 0.99983 & 1.00000 & $232,678,663,944.75$ & 25.00 & $301,868,318,830.75$ & 34.00 \\
\hline 10 & $78,373,386,283.00$ & $78,432,262,584.73$ & $78,432,262,584.73$ & $58,876,302$ & 0 & 1.00075 & 1.00000 & $223,217,731,767.72$ & 24.00 & $301,591,118,050.72$ & 34.00 \\
\hline 11 & $78,373,386,283.00$ & $83,641,993,701.51$ & $83,641,993,701.51$ & $5,268,607,419$ & 0 & 1.06722 & 1.00000 & $204,432,806,125.46$ & 23.00 & $282,806,192,408.46$ & 34.00 \\
\hline 12 & $88,722,424,391.00$ & $88,851,724,818.29$ & $88,851,724,818.29$ & $129,300,427$ & 0 & 1.00146 & 1.00000 & $212,656,040,796.31$ & 22.00 & $301,378,465,187.31$ & 34.00 \\
\hline 13 & $88,722,424,391.00$ & $92,255,000,760.68$ & $92,255,000,760.68$ & $3,532,576,370$ & 0 & 1.03982 & 1.00000 & $201,538,225,266.86$ & 21.00 & $290,260,649,657.86$ & 34.00 \\
\hline 14 & $95,597,678,565.00$ & $95,691,766,929.46$ & $95,691,766,929.46$ & $94,088,364$ & 0 & 1.00098 & 1.00000 & $205,923,242,800.74$ & 20.00 & $301,520,921,365.74$ & 34.00 \\
\hline 15 & $102,804,265,166.00$ & $102,796,782,096.89$ & $102,796,782,096.89$ & $-7,483,069$ & 0 & 0.99993 & 1.00000 & $199,035,387,403.84$ & 19.00 & $301,839,652,569.84$ & 34.00 \\
\hline 16 & $114,840,695,578.00$ & $114,841,627,931.82$ & $113,331,285,147.52$ & 932,354 & $1,510,342,784$ & 1.00001 & 1.01333 & $186,974,535,901.63$ & 17.76 & $301,815,231,479.63$ & 33.76 \\
\hline 17 & $114,840,695,578.00$ & $122,236,161,136.36$ & $121,002,305,385.68$ & $7,395,465,558$ & $1,233,855,751$ & 1.06440 & 1.01020 & $168,716,577,454.10$ & 16.83 & $283,557,273,032.10$ & 33.83 \\
\hline 18 & $123,620,003,381.00$ & $123,624,522,472.73$ & $130,703,557,075.45$ & $4,519,092$ & $-7,079,034,603$ & 1.00004 & 0.94584 & $178,186,645,498.40$ & 16.92 & $301,806,648,879.40$ & 34.92 \\
\hline 19 & $130,203,867,537.00$ & $130,204,147,936.36$ & $144,304,306,310.36$ & 280,399 & $\begin{array}{l}- \\
14,100,158,374\end{array}$ & 1.00000 & 0.90229 & $171,613,164,305.84$ & 16.62 & $301,817,031,842.84$ & 35.62 \\
\hline 20 & $130,203,867,537.00$ & $144,117,943,068.18$ & $157,470,341,949.41$ & $13,914,075,531$ & $\begin{array}{l}- \\
13,352,398,881\end{array}$ & 1.10686 & 0.91521 & $142,474,389,084.99$ & 15.30 & $272,678,256,621.99$ & 35.30 \\
\hline 21 & $141,521,728,985.00$ & $148,901,753,325.00$ & $170,636,377,588.47$ & $7,380,024,340$ & $\begin{array}{l}- \\
21,734,624,263\end{array}$ & 1.05215 & 0.87263 & $145,336,949,407.62$ & 14.90 & $286,858,678,392.62$ & 35.90 \\
\hline 22 & $152,360,944,656.00$ & $153,685,563,581.82$ & $183,802,413,227.53$ & $1,324,618,926$ & - & 1.00869 & 0.83615 & $146,855,364,566.31$ & 14.35 & $299,216,309,222.31$ & 36.35 \\
\hline 23 & $170,962,056,391.00$ & $172,518,986,927.27$ & $203,549,882,680.41$ & $1,556,930,536$ & $\begin{array}{l}- \\
31,030,895,753\end{array}$ & 1.00911 & 0.84755 & $128,131,814,132.09$ & 12.98 & $299,093,870,523.09$ & 35.98 \\
\hline 24 & $182,018,842,243.00$ & $176,487,889,443.18$ & $207,826,542,672.29$ & $-5,530,952,800$ & $\begin{array}{l}- \\
31,338,653,229\end{array}$ & 0.96961 & 0.84921 & $129,257,501,909.20$ & 11.78 & $311,276,344,152.20$ & 35.78 \\
\hline
\end{tabular}

\section{KESIMPULAN}

Pada Proyek Jumeriah Pecatu Beach Resort, biaya yang diperlukan untuk menyelesaikan pekerjaan yang tersisa yaitu Rp.129.275.501.909,20 sedangkan waktu yang diperlukan adalah 11,78 bulan. Untuk kinerja biaya proyek ditunjukan pada nilai indeks kinerja biaya 0,96961 dan kinerja waktu yang ditunjukan pada nilai indeks kinerja jadwal yaitu 0,84921. Dengan asumsi keadaan akan tetap sama seperti saat pelaporan bulan ke-24, untuk perkiraan biaya dan waktu akhir didapat nilai untuk biaya sebesar Rp.311.276.344.152,2 dimana mengalami pembengkakan sebesar 3,134\% dan total waktu penyelesaian proyek yaitu 35,78 bulan, dimana mengalami keterlambatan 1,78 bulan dari rencana 34 bulan. 


\section{SARAN}

Hal-hal yang dapat disarankan yaitu, selalu mengevaluasi penggunaan biaya dan waktu setiap bulannya pada pelaksanaan proyek. Hal ini bermanfaat jika proyek mengalami keterlambatan maka dapat diantisipasi jumlah biaya dan waktu pelaksanaan proyek yang diperlukan agar proyek dapat selesai dengan tuntas. Penjadwalan ulang kegiatan proyek dapat menggunakan aplikasi Microsoft Project, jika jumlah kegiatan utama dan sub-kegiatan proyek cukup banyak, dan dapat mengalami kesulitan membuat penjadwalan secara manual.

\section{DAFTAR PUSTAKA}

Auzan, R. N, Rizky, D. S., Suharyanto, dan Kistiani, F., (2017), Pengendalian Biaya dan Waktu Proyek dengan Metode Konsep Nilai Hasil (Earned Value), JURNAL KARYA TEKNIK SIPIL, Vol. 6, No. 4, Hal. 460-470.

Castollani, A., Puro, S. dan Dewa, M. L., (2020), Analisis Biaya dan Waktu pada Proyek Apartemen dengan Metode Earned Value Concept, Jurnal Rekayasa Konstruksi Mekanika Sipil, Vol. 3, No. 1, Hal. 39-48.

Gardjito, E., (2017), Pengendalian Jadwal dan Anggaran Terpadu dengan Metode Earned Value Analysis pada Pekerjaan Konstruksi, UkaRsT, Vol.1, No.1, Hal. 19-26.

Husen, A., (2011), Manajemen Proyek: Perencanaan, Penjadwalan, \& Pengendalian Proyek, Edisi Revisi, Yogyakarta: ANDI.

Kartikasari, D., (2014), Pengendalian Biaya Dan Waktu Dengan Metode Earned Value (Studi Kasus: Proyek Struktur dan Arsitektur Production Hall-02 Pandaan), EXTRAPOLASI, Vol. 7, No. 2, Hal. 107-114.

Maromi, M. I., dan Indryani, R., (2015), Metode Earned Value untuk Analisa Kinerja, Biaya dan Waktu Pelaksanaan pada Proyek Pembangunan Condotel De Vasa Surabaya, JURNAL TEKNIK ITS Vol. 4, No. 1, Hal. 54-59.

Prasetya, E. B., (2018), Aplikasi Manajemen Proyek Konstruksi dengan Metode Critical Path dan Earned Value Management, RESISTOR, Vol. 1, No. 2, Hal. 11-26.

Sediyanto, dan Hidayat, A., (2017), Analisa Kinerja Biaya dan Waktu pada Pelaksanaan Proyek Konstruksi dengan Metode Earned Value (Studi Kasus Proyek Konstruksi Mall dan Hotel X di Pekanbaru), Jurnal Ilmu Teknik dan Komputer, Vol. 1, No. 1, Hal. 36-51.

Soeharto, I., (1997), Manajemen Proyek (Dari Konseptual Sampai Operasional), Erlangga, Jakarta.

Soeharto, I., (1999), Manajemen Proyek I (Dari Konseptual Sampai Operasional), Erlangga, Jakarta.

Soeharto, I., (2001), Manajemen Proyek 2, Erlangga, Jakarta.

Widiasanti, I., dan Lenggogeni, (2014), Manajemen Konstruksi, PT. Remaja Rosdakarya,

Bandung.

Willar, D., dan Pangemanan, D. D. G., (2020), Hambatan Signifikan Implementasi Sistem Manajemen Mutu Pelaksana Konstruksi, TEKNIK, 41 (2), 2020, Hal. 100-110.

Willar, D., dan Trigunarsyah, B., (2021), Hambatan Penerapan Konstruksi Berkelanjutan: Perspektif Pemerintah, Media Komunikasi Teknik Sipil, Vol. 27, No.1, 2021, Hal. 18-28.

Zakariyya, B., Ridwan, A., dan Suwarno, (2020), Analisis Biaya dan Jadwal Proyek Pembangunan Gedung Dinas Kesehatan Kabupaten Trenggalek dengan Metode Earned Value, JURMATEKS, Vol. 4, No. 2, Hal. 363-376. 